\title{
Complete endoscopic management of a retained bullet in the bladder
}

\author{
Ariella A. Friedman, MD; ${ }^{*}$ Quoc-Dien Trinh, MD, FRCSC; ${ }^{* *}$ Sanjeev Kaul, MD; ${ }^{-\xi}$ Akshay Bhandari, MD* \\ *Vattikuti Urology Institute, Henry Ford Health System, Detroit, MI; 'Cancer Prognostics and Health Outcomes Unit, University of Montreal Health Centre, Montreal, QC; § Department of Urology, Oakland \\ University School of Medicine, Detroit, Ml; *Department of Urology, Columbia University, New York, NY
}

Cite as: Can Urol Assoc J 2013;7:E143-E145. http://dx.doi.org/10.5489/cuaj.258

\section{Abstract}

A 25-year-old male gunshot victim presented at our institution with gross hematuria following Foley catheter insertion. Computed tomography and cystogram did not show a bladder perforation, but were notable for a left ischial fracture and the presence of a bullet within the bladder. After failed attempts at retrieving the bullet with a resectoscope and loop, as well as a cystoscope and stone crusher, a 26 French nephroscope was inserted transurethrally, and the bullet was successfully engaged and removed using a Perc NCircle (Cook Medical, Bloomington, IN) grasper. The extraperitoneal injury was managed conservatively with catheter drainage. To our knowledge, this represents the first case of successful transurethral management of a retained intravesical bullet. Such an approach may benefit patients with retained intravesical bullets or other challenging intravesical foreign bodies and may be helpful in select circumstances to spare patients from more extensive surgeries.

\section{Case report}

We present a 25-year-old male gunshot victim with gross hematuria noted after Foley catheter insertion. He had a history of urethral disruption, also from a gunshot wound, requiring open cystotomy and antegrade catheter insertion. A computed tomography (CT) and cystogram did not show a bladder perforation, but were notable for a left ischial fracture and the presence of a bullet within the bladder (Fig. 1).

Proctoscopy was negative for a rectal injury, and cystourethroscopy demonstrated a left anterolateral bladder wall defect, where the bullet had entered the bladder, as well as an intravesical bullet (Fig. 2, part A). After failed attempts at retrieving the bullet with a resectoscope and loop, as well as a cystoscope and stone crusher, a 26 French nephroscope was inserted transurethrally, and the bullet was successfully engaged and removed using a Perc NCircle (Cook Medical, Bloomington, IN) grasper (Fig. 2, part B). The extraperitoneal injury was managed conservatively with catheter drainage (Fig. 3).

\section{Discussion}

Injuries to the genitourinary system among civilians sustaining gunshot wounds are uncommon, occurring in up to $10.5 \%$ of cases. ${ }^{1}$ The bladder is the third most commonly injured urogenital organ overall in the trauma setting $(13 \%$ to $19 \%)$, behind the kidney $(17 \%$ to $55 \%)$ and scrotum $(21 \%$ to $26 \%)^{1-5}$ In most cases of genitourinary bullet injury, injury to non-genitourinary organs concomitantly occurs (85\% to $92 \%$ ), and the possibility of minimally invasive management is often precluded. Operative intervention for bladder injury due to gunshot injury typically includes laparotomy and primary repair, especially when the injury is intraperitoneal.

Successful conservative management of gunshot-related extraperitoneal bladder injury with Foley catheter drainage has been described in multiple prospective and retrospective studies, ${ }^{6}$ though not in the specific setting of a retained intravesical bullet. Reports of retained intravesical bullets are rare, and the literature generally does not distinguish management of this particular entity as separate from management of bladder injury due to gunshot in general. This situation is unique in that an exploratory procedure may not truly be necessary if concomitant organ injury is absent and the perforation is extraperitoneal, but conservative management with catheter drainage alone does not address the retained bullet.

Management of the retained bullet can vary with the nature of injury, circumstances surrounding the injury, and the means available to the operative surgeon. Specifically, spontaneous passage of intravesical bullets per urethra upon voiding has been reported, usually in the setting of an unrecognized bladder injury. ${ }^{7-10}$ In other cases, however, a retained intravesical bullet has led to urinary retention. ${ }^{11}$ Also, calculus formation due to heterogeneous enucleation and infection can occur if removal is delayed. ${ }^{12}$ As such, it is recommended that an intravesical bullet be actively removed. Although transurethral unroofing with laparoscop- 


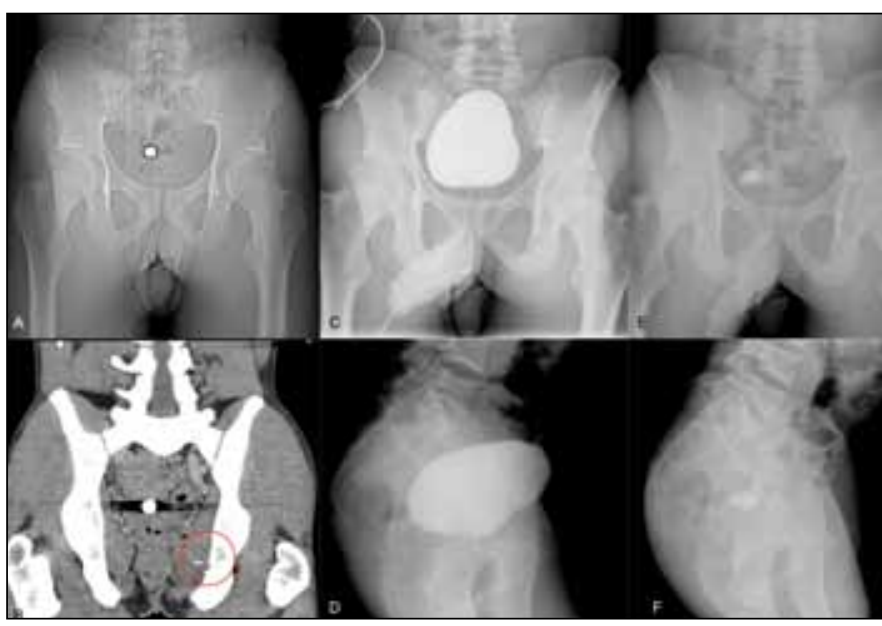

Fig. 1. (A) Scout film on computed tomography demonstrates a bullet overlying the bladder area. (B) The bullet entered the left buttocks, ricocheted off of the left ischium, causing an ischial fracture (red circle, B), and entered the bladder through its anterior wall. The filling phase of cystogram (C, D) demonstrated no bladder wall defect and obscured the bullet, which was later demonstrated on post-drainage films (E, F).

ic removal has previously been described, ${ }^{13}$ to our knowledge, the current article represents the first description of exclusive transurethral retrieval of a bullet.

The successful use of a transurethral nephroscope for intravesical object retrieval has been previously described, most often to help in treating large bladder stones. Successful retrieval is facilitated by the ability to remove bigger stone fragments through the larger nephroscope sheath. Moreover, use of the nephroscope allows for the introduction of tools with firm gripping capabilities that are too large to be used with a standard 21 or 22 French cystoscope (i.e., the Perc NCircle device). This is particularly useful when cystoscopecompatible graspers are unsuccessful, as was the case in this patient. Relative to cystoscopic ${ }^{14}$ and percutaneous ${ }^{15}$ treatment of bladder stones, prospective trials have shown that the use of a nephroscope has been associated with shorter operative times, avoidance of intraoperative complications

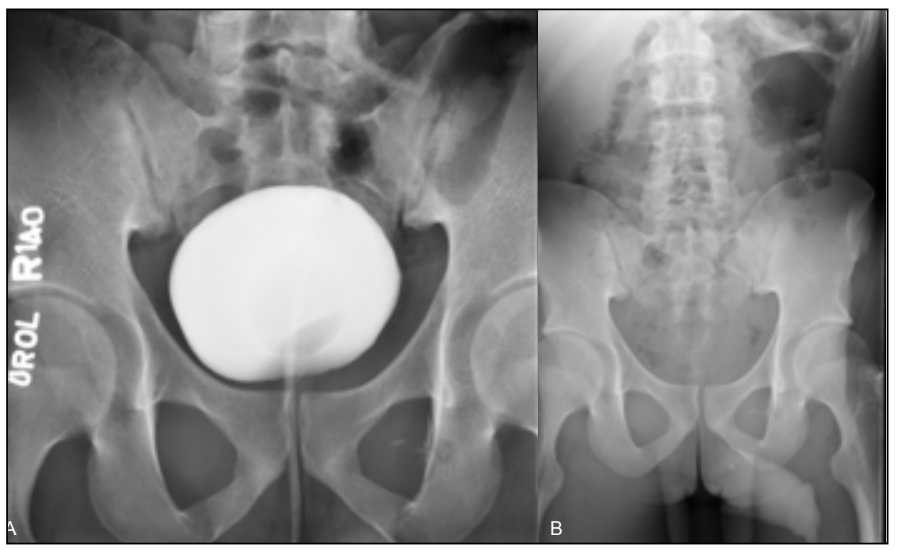

Fig. 3. $(A, B)$ The patient's extraperitoneal bladder injury was successfully managed with catheter drainage, demonstrated by a negative cystogram performed on postoperative day 13 , at which point the catheter was removed.

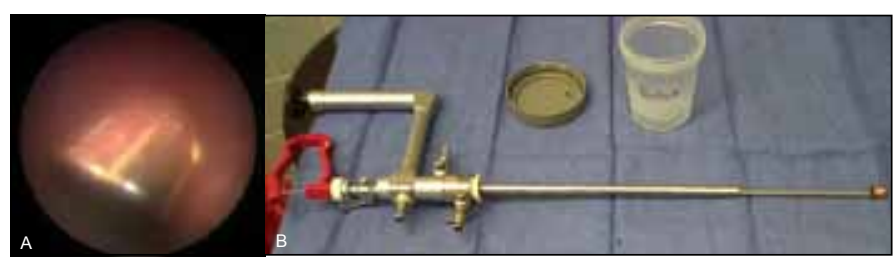

Fig. 2. (A) Cystoscopic image of the intravesical bullet. (B) The bullet was successfully retrieved using a Perc NCircle (Cook Medical, Bloomington, IN) grasper.

and avoidance of postoperative de novo stricture development (while stricture recurrence in those with previous known stricture disease has been described, it occurs with no greater frequency than in those undergoing analogous procedures with the use of a cystoscope). ${ }^{14}$ In addition to bladder calculi, the nephroscope has also been used in the retrieval of self-placed intravesical foreign bodies, including a thermometer ${ }^{16}$ and screws. ${ }^{17}$

One limitation of complete transurethral endoscopic management of an intravesical bullet is the inability to inspect for simultaneous ureteral injury, which is diagnosed in up to $9 \%$ of cases during open surgical exploration for cystorrhaphy. ${ }^{18}$ Therefore, complete endoscopic management would presumably be appropriate for patients with a low index of suspicion for ureteral injury, while retrograde pyelogram may be a useful adjunct in select cases.

\section{Conclusion}

We describe the first case of successful transurethral management of a retained intravesical bullet, which was performed with the use of a nephroscope. Such an approach may benefit patients with retained intravesical bullets or other challenging intravesical foreign bodies and may be helpful in select circumstances to spare patients from more extensive surgeries.

Competing interests: None declared.

This paper has been peer-reviewed.

\section{References}

1. Naijbi S, Tannast $M$, Latini JM. Civilian gunshot wounds to the genitourinary tract: incidence, anatomic distribution, associated injuries, and outcomes. Urology 2010;76:977-81; discussion 981. http://dx.doi. org/10.1016/i.urology.2010.01.092

2. Hudolin T, Hudolin I. Surgical management of urogenital injuries at a war hospital in Bosnia-Hrzegovina, 1992 to 1995. J Urol 2003;169:1357-9. http://dx.doi.org/10.1097/01.ju.0000051220.77880.64

3. Salvatierra $0 \mathrm{Jr}$, Rigdon WO, Norris DM, et al. Vietnam experience with 252 urological war injuries. J Urol 1969;101:615-20.

4. Vuckovic I, Tucak A, Gotovac J, et al. Croatian experience in the treatment of 629 urogenital war injuries. J Trauma 1995;39:733-6. hitp://dx.doi.org/10.1097/00005373-199510000-00023

5. Thompson IM, Flaherty SF, Morey AF. Battlefield urologic injuries: the Gulf War experience. J Am Coll Surg 1998;187:139-41. hitp://dx.doi.org/10.1016/S1072-7515(98)00120-3 
Endoscopic management of a retained bullet in the bladder

6. Navsaria PH, Edu S, Nicol AJ. Nonoperative management of pelvic gunshot wounds. Am I Surg 2011;201:784-8. http://dx.doi.org/10.1016/i.amisurg.2010.03.014

7. Cohen SP, Varma KR, Goldman SM. Spontaneous expulsion of intravesical bullet. Urology 1975;5:387-9. http://dx.doi.org/10.1016/0090-4295(75)90163-6

8. Sankari BR, Parra RO. Spontaneous voiding of a bullet after a gunshot wound to the bladder: case report. J Trauma 1993;35:813-4. http://dx.doi.org/10.1097/00005373-199311000-00030

9. Kilic D, Kilinc F, Ezer A, et al. Spontaneous expulsion of a bullet via the urethra. Int J Urol 2004;11:576-7. http://dx.doi.org/10.1111/i.1442-2042.2004.00826.x

10. Abdelsayed MA, Bissada NK, Finkbeiner AE, et al. Spontaneous passage of bullet during voiding. South Med J 1978;71:83-4. http://dx.doi.org/10.1097/00007611-197801000-00027

11. Raz 0, Shilo Y, Stav K, et al. Late migration of a retained bullet into the urinary bladder presenting with acute urinary retention. Isr Med Assoc J 2007;9:484-5.

12. Macpherson EM. A Case of Gunshot wound, and subsequent extraction of a bullet from the bladder. Med Chir Trans1850;33:197-200.

13. Halkic N, Wisard M, Abdelmoumene A, et al. A large bullet in the bladder. Swiss Surg 2001;7:139-40. http://dx.doi.org/10.1024/1023-9332.7.3.139
14. Ener K, Agras K, Aldemir M, et al. The randomized comparison of two different endoscopic techniques in the management of large bladder stones: transurethral use of nephroscope or cystoscope? J Endourol 2009;23:1151-5. http://dx.doi.org/10.1089/end.2008.0647

15. Singh KJ, Kaur J. Comparison of three different endoscopic techniques in management of bladder calculi. Indian J Urol 2011;27:10-3. http://dx.doi.org/10.4103/0970-1591.78402

16. Nishiyama K, Shimada T, Yagi S, et al. Endoscopic removal of intravesical thermometer using a rigid nephroscope and forceps. Int J Urol 2002;9:717-8. http://dx.doi.org/10.1046/j.1442-2042.2002.00545.x

17. Schnall RI, Baer HM, Seidmon EJ. Endoscopy for removal of unusual foreign bodies in urethra and bladder. Urology 1989;34:33-5. http://dx.doi.org/10.1016/0090-4295(89)90152-0

18. Perez Fentes DA, Toucedo Caamano V, Villasenin Parrado L, et al. Gunshot bladder trauma: case report and literature review [in Spanish]. Actas Urol Esp 2006;30:947-53. http://dx.doi.org/10.4321/ S0210-48062006000900014

Correspondence: Dr. Ariella Friedman, Vattikuti Urology Institute, Henry Ford Health System, 2799 W. Grand Boulevard, Detroit, Ml; fax: 313-916-2956; afriedm1@hfhs.org 